\title{
Optical coherence tomography enhanced by novel software to better visualize the mechanism of atherosclerosis and improve the effects of percutaneous coronary intervention
}

\author{
Stanisław Bartuś1,2, Łukasz Rzeszutko ${ }^{1,2}$, Rafał Januszek ${ }^{1}$ \\ 'Department of Cardiology and Cardiovascular Interventions, University Hospital, Kraków, Poland \\ 2Jagiellonian University Medical College, Kraków, Poland
}

\author{
Correspondence to: \\ Rafał Januszek, MD, PhD, \\ Department of Cardiology and \\ Cardiovascular Interventions, \\ University Hospital, \\ Jakubowskiego 2, 30-688 \\ Kraków, Poland \\ phone: +48 124002250 , \\ e-mail: jaanraf@interia.pl \\ Copyright by the Author(s), 2022 \\ DOI: 10.33963/KP.a2021.0171 \\ Received: \\ September 25, 2021 \\ Accepted: \\ December 5, 2021 \\ Early publication date: \\ December 5, 2021
}

Optical coherence tomography (OCT) uses near-infrared light to provide high-definition images of the artery. The OCT provides automated, accurate measurements to help guide stent sizing and post-stent optimization among patients treated with percutaneous coronary interventions (PCls) [1, 2]. OCT has also been proven to be significantly related to long-term clinical outcomes [3].

We present the case of a 65 -year-old man with a history of prior $\mathrm{PCl}$ to the circumflex artery with drug-eluting stent (DES) implantation in 2006. Additionally, the patient suffered from arterial hypertension, diabetes mellitus, hyperlipidemia, chronic obstructive pulmonary disease, ventricular extrasystolia, and was a heavy smoker in the past. Two months earlier, the patient was treated with $\mathrm{PCl}$ of the left anterior descending artery with DES implantation, and due to borderline stenoses in the right coronary artery (RCA), the patient underwent FFR measurement (PressureWire $^{\mathrm{TM}} \mathrm{X}$, Abbott Vascular, Santa Clara, CA, USA). Hyperemia was induced by an intracoronary bolus of $200 \mu \mathrm{g}$ adenosine. The instantaneous wave-free ratio (iFR) was 0.96 and FFR 0.77. The pull-back demonstrated two distinct gradients in the distal segment before bifurcation and in the medial segment (Figure 1A). After introducing the Balance Middle-weight Universal II guidewire (Abbott Vascular), we performed OCT (Dragonfly OpStar, Abbott Vascular) of the RCA with the use of Ultreon ${ }^{\mathrm{TM}}$ Software (Abbott Vascular) (Figure 1B-D). Afterward, pre-dilatation with the non-compliant Solarice (Medtronic, Minneapolis, MN, USA) catheter balloon was carried out in the distal $(2.0 \times 12 \mathrm{~mm}, 12-$ $-14 \mathrm{~atm})$ and medial segments $(3.0 \times 20 \mathrm{~mm}$, 12-14 atm). Based on the results of the OCT examination, $3.5 \times 38 \mathrm{~mm}$ and $3.5 \times 12 \mathrm{~mm}$, 18 atm DES Xience Pro stents were implanted (Figure 1E). An additional stent was implanted into the distal segment of the RCA and the right posterior descending artery (DES Xience Pro $2.5 \times 15 \mathrm{~mm}, 18 \mathrm{~atm}$ ). Due to the suboptimal stent expansion demonstrated by $\mathrm{OCT}$, post-dilatation was conducted with $2.5 \times 15 \mathrm{~mm}, 3.0 \times 15 \mathrm{~mm}$, and $4.0 \times 15 \mathrm{~mm}$ non-compliant catheter balloons alongside the proximal optimization technique up to 24 atm. The optimal, final effect was confirmed via OCT (Figure 1E).

In conclusion, the presented modern software offers precise guidance following the assessment of morphology, lesion length, and artery diameter to aid decision-making at every step of the $\mathrm{PCl}$ [4]. It helps determine proper treatment technique pre-PCI and assess the $\mathrm{PCl}$ result including potential dissections, stent apposition, and expansion. The Ultreon ${ }^{\mathrm{TM}}$ Software can detect the degree and thickness of calcification and can display calcification angle and maximal thickness values throughout the pullback in real-time. The highlighted calcifications overlay on the vessel with the co-registration view. Using this software, we can visualize the external elastic lamina and artery lumen diameter, which helps in identifying landing zones for accurate stent placement. Side-by-side viewing of live and co-registered angiography enables precise stent deployment. We have a better opportunity to ensure the completeness of 

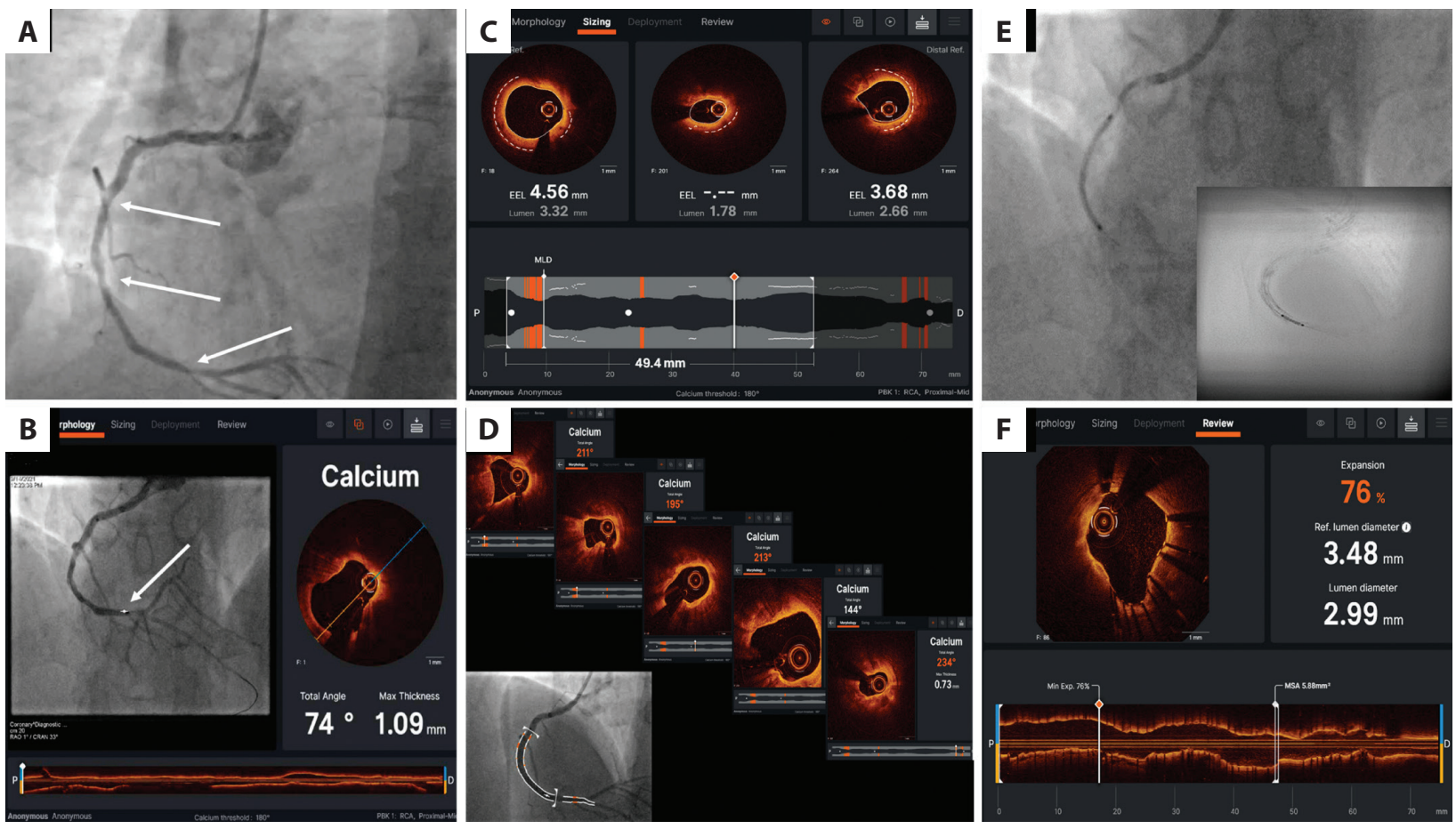

Figure 1. A. Coronary angiography of the RCA before PCI (white arrows indicate stenoses). B. OCT with co-registration before stent implantation - intuitive workflow interface (white arrow indicates the position marker of the OCT image in a cross-section). C. Cross-sectional images in OCT before stent placement — sizing interface images. D. Cross-sectional images in OCT before stent placement — an assessment of calcifications with co-registration. E. Coronary angiography of RCA — proximal stents implantation. F. Control OCT after stent implantation - longitudinal cross-section

Abbreviations: $\mathrm{OCT}$, optical coherence tomography; $\mathrm{PCl}$, percutaneous coronary intervention; RCA, right coronary artery

lesion coverage and avoid landing the stent edges on unfavorable morphology. We are also assisted in ensuring optimal stent expansion and apposition with the instantaneous display of expansion and apposition results.

\section{Article information}

Conflict of interest: None declared.

Open access: This article is available in open access under Creative Common Attribution-Non-Commercial-No Derivatives 4.0 International (CC BY-NC-ND 4.0) license, allowing to download articles and share them with others as long as they credit the authors and the publisher, but without permission to change them in any way or use them commercially. For commercial use, please contact the journal office at kardiologiapolska@ptkardio.pl.

\section{REFERENCES}

1. Räber L, Mintz GS, Koskinas KC, et al. Clinical use of intracoronary imaging. Part 1: guidance and optimization of coronary interventions. An expert consensus document of the European Association of Percutaneous Cardiovascular Interventions. Eur Heart J. 2018; 39(35): 3281-3300, doi: 10.1093/eurheartj/ehy285, indexed in Pubmed: 29790954.

2. Johnson TW, Räber L, di Mario C, et al.Clinical use of intracoronary imaging. Part 2: acute coronary syndromes, ambiguous coronary angiography findings, and guiding interventional decision-making: an expert consensus document of the European Association of Percutaneous Cardiovascular Interventions. Eur Heart J. 2019; 40(31): 2566-2584, doi: 10.1093/eurhearti/ehz332, indexed in Pubmed: 31112213.

3. Prati F, Romagnoli E, Burzotta F, et al. Clinical Impact of OCT Findings During PCl: The CLI-OPCI II Study. JACC Cardiovasc Imaging. 2015; 8(11): 1297-1305, doi: 10.1016/j.jcmg.2015.08.013, indexed in Pubmed: 26563859.

4. Ultreon ${ }^{\text {TM }} 1.0$ Software IFU. Refer to Instructions For Use (IFU) for additional information. Available online: www.cardiovascular.abbott/int/en/hcp/products/percutaneous-coronary-intervention/intravascular-imaging/ultreon-software/about.html. 